\title{
Action for adolescent girls and COVID-19: Implications for safe space programming in the Sahel
}

Population Council

Follow this and additional works at: https://knowledgecommons.popcouncil.org/departments_sbsr-pgy How does access to this work benefit you? Let us know!

\section{Recommended Citation}

"Action for adolescent girls and COVID-19: Implications for safe space programming in the Sahel," SWEDD Project Brief. New York: Population Council, 2021. 


\section{ACTION FOR ADOLESCENT GIRLS \& COVID-19: IMPLICATIONS FOR SAFE SPACE PROGRAMIMING IN THE SAHEL}

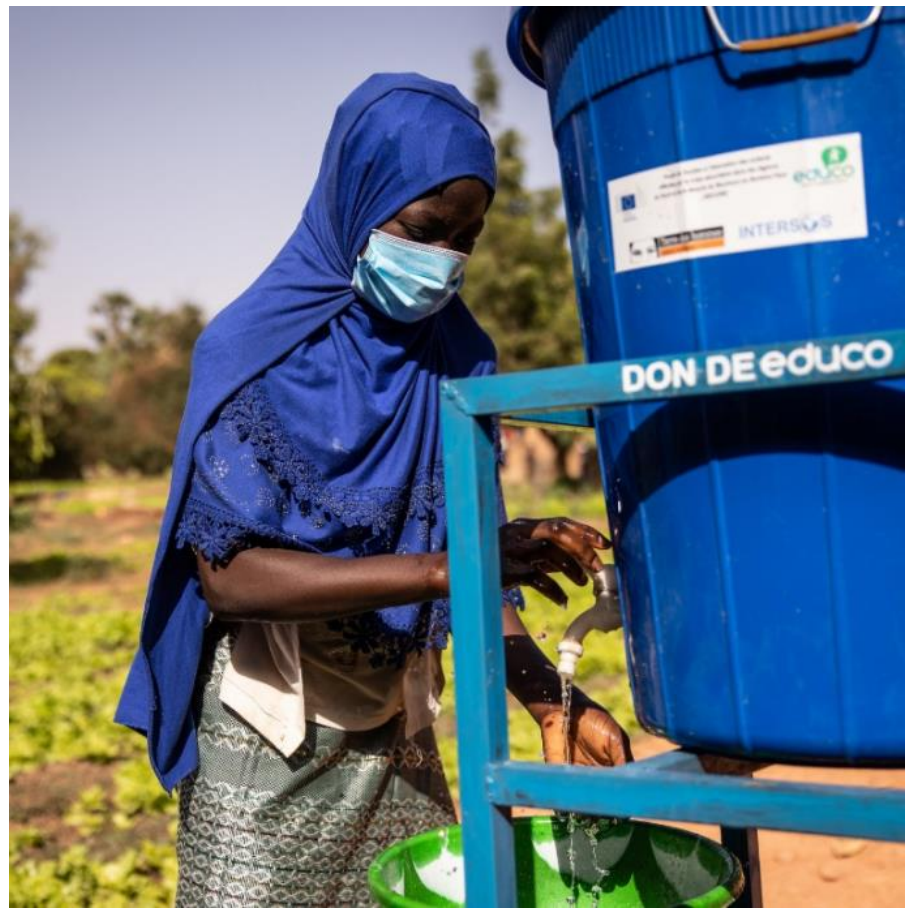

\section{RECOMMENDATIONS}

1. Modify settings for in-person safe spaces

2. Connect with Adolescent Girls by phone

3. Use mentors to deliver health messages and products

4. Expand program priorities to respond to shocks

\section{Economic Strengthening}

This brief presents strategies that have been used by organizations to adapt programs for adolescent girls (AG) during crises. It aims to inform SWEDD planners and implementing partners to revitalize and/or maintain safe space programming. This can be essential to maintain contact with and support for AG during the COVID-19 pandemic. It is imperative that SWEDD be a driver of change by prioritizing AGs and mentors' safety in the context of the pandemic and other crises.

The strategies below have been used, and in some cases studied, to adapt AG programs such as safe space programs to the constraints imposed under COVID-19. Based on these experiences, we recommend promising strategies that may be implemented to "learn while doing" during crises in SWEDD contexts. SWEDD management units, implementing partners, ministries representatives, and technical assistance partners should consider these recommendations and how they might be useful in the contexts where they work. All recommendations should be adapted to each country and target population.

\section{COVID-19 EFFECTS ON ADOLESCENTS}

The global COVID-19 pandemic poses primary risks (i.e., COVID infection) and secondary risks (i.e., school closures, lock downs, household economic instability) for communities, families, and AG specifically.

In the Sahel region, governments and NGOs in countries such as Burkina Faso, Mali, and Niger report that the need for humanitarian assistance for children has increased. ${ }^{1}$

1 UN News. Violence, COVID-19, Contribute to Rising Humanitarian Needs in the Sahel. https://news.un.org/en/story/2020/10/1075602 
Longstanding threats to girls' wellbeing and gender inequity mean that these circumstances are likely to disproportionately impact AG2 . A CARE survey of COVID-19-related effects on gender norms in 12 West African countries found reduced access to health care (52\% women, $42 \%$ men), including reproductive health services, due to mistrust of health workers and fear of contracting COVID-19. ${ }^{3}$ Studies of adolescents elsewhere reveal low levels of knowledge of asymptomatic COVID-19 transmission as well as adherence to protective guidelines (e.g., wearing face masks) and threats to adolescents' education, food security, and mental health. ${ }^{4,5}$ Research is needed on gendered differences in COVID-19 effects in Sahelian pastoralist communities in particular. In these communities, women and girls remain on a homestead while men and boys travel with livestock. Risk of COVID-19 exposure and secondary effects are likely to differ for girls and boys due to varied access to land for grazing. $6,7,8$

\section{CONSIDERATIONS FOR SAFE SPACE PROGRAMIMING UNDER COVID-19}

Programs for AG in low and middle-income countries have used different strategies to mitigate the primary and secondary risks of COVID-19, including adjusting their structures and/or aims. The following examples illustrate the types of tactics organizations have used in contexts with similar features to the Sahel region. These may provide useful lessons for SWEDD programming. It is vital to adapt these approaches to the specific features of program context and the target sub-population or AG segment. For information on the importance of responding to adolescents' heterogeneity using segmentation, refer to the Minimum Standards Guide for SWEDD Safe Spaces. Planners should determine which adolescent girls' urgent needs to prioritize to ensure that adapted SWEDD programming can continue to support and protect vulnerable AG during crises like COVID-19.

\footnotetext{
2 UN News. Violence, COVID-19, Contribute to Rising Humanitarian Needs in the Sahel. https://news.un.org/en/story/2020/10/1075602

3 Relief Web. (2021). New CARE report: how COVID-19 is changing gender norms in West Africa. https://reliefweb.int/report/benin/new-care-reporthow-covid-19-changing-gender-norms-west-africa

4 "Social, health, education and economic effects of COVID -19 on adolescent girls in Kenya: Responses from the first round of adolescent data collection, August 2020-Wajir," COVID-19 Research \& Evaluations brief. Nairobi: Population Council, 2020.

${ }^{5}$ Amin, Sajeda, Ubaidur Rob, Sigma Ainul, Md. Irfan Hossain, Forhana Rahman Noor, Iqbal Ehsan, and Mehnaz Manzur. 2020. "Bangladesh: COVID-19 Knowledge, Attitudes, Practices \& Needs-Responses from three rounds of data collection among adolescent girls in districts with high rates of child marriage," COVID-19 Research \& Evaluations brief. Dhaka:

Population Council
}

\section{Modify In-Person Safe Spaces}

\section{$\underline{\text { Recommendations }}$}

- Secure outdoor options for safe spaces, continuing to pay special attention to the privacy of program mentors and participants.

- Hold smaller in-person group meetings where social distancing and face coverings are used.

- Hold extra weekly sessions to accommodate the original number of participants through multiple, smaller group sessions.

\section{Lessons from Experience}

Experiences with reduced-capacity groups show that it is feasible to follow physical distancing guidelines ${ }^{9}$ while still providing AG with opportunities for vital inperson connections. After an initial shutdown, REPACTED in Kenya resumed modified groups limited to a maximum of 10 participants. The modified safe space model using smaller group size also enabled Nigeria's Education as a Vaccine (EVA) project to reconnect with mentors and reinitiate girls' safe spaces with physically distant smaller groups. ${ }^{10}$

Another strategy to protect mentors and participants is to modify the location and structure of meetings to adhere to local and global guidance. The Batonga Foundation in Benin has tested modified safe spaces that meet outside. Participants follow national social distancing recommendations, mentors wear masks, and activities and games avoid physical touch. ${ }^{11}$ Additional information is shared between participants and mentors using voice recordings. These modified safe spaces were implemented in rural areas during a period when community transmission was limited to the economic capital of Cotonou.

\section{The Minimum Standards Guide for SWEDD Safe} Spaces $^{12}$ emphasizes the importance of using 'segmentation' to sub-divide groups of AGs based on similar characteristics. An adapted model with smaller group sizes may make it possible to apply segmentation by organizing dedicated sessions for AG who share several characteristics (e.g., married

8 USAID. (2021). USAID/Sahel Regional Office COVID-Specific Gender Analysis. https://reliefweb.int/report/benin/new-care-report-how-covid-19 changing-gender-norms-west-africa.

9 African Union, Africa CDC. “Africa Centers for Disease Control and Prevention Guidance on Community Physical Distancing During COVID-19 Pandemic; Physical Distancing, Social Support"

https://africacdc.org/download/guidance-on-community-social-distancingduring-covid-19-outbreak/

10 Briggs, Hannah, Nicole Haberland, Sapna Desai, Thomas de Hoop, and Thoai Ngo. 2020. "The impact of COVID-19 on opportunities for adolescent girls and the role of girls' groups," brief, Evidence Consortium on Women's Groups.

11 Adaptations in Crisis is a webinar presented by the Population Council's Adolescent Girls Community of Practice, focused on disseminating information on different models and experiences of girls' programs during COVID-19.

12 Population Council. 2021. Le Guide des normes minimales pour des espaces sûrs : la conception, la mise en œuvre, et le suivi, l'évaluation et l'apprentissage. New York.

https://www.popcouncil.org/uploads/pdfs/2021PGY GuideNormesMinimal esEspacesSurs.pdf 
girls; out-of-school girls aged 10-14). This strategy can make it possible to tailor content for the distinct life circumstances of AG with similar lived experiences.

\section{Connect with Adolescent Girls by Phone}

\section{Recommendations}

- Use of smart phones may be effective for maintaining contact with $A G$ and monitoring for secondary risks or other needs emerging within the household during the pandemic.

- Although some AGs access mobile phones by borrowing from friends and family, AG are less likely than adolescent boys or adults to own or have access to phones, ${ }^{13}$ especially marginalized girls like child domestic workers.

- Consider contextual factors such as phone penetration in the population and social or cultural norms around AG's mobile phone use that influence the feasibility and safety of connecting with the most vulnerable AG using phones.

- Use mobile phones to create flexible opportunities for engagement, (i.e., interactive 'challenges' for AG to accomplish each week) to increase and/or sustain a program's ability to connect with AG.

- Flexible scheduling and multiple channels of communication (text messages, phone calls and in-person meetings etc.) are likely to improve program success in reaching AG using phones.

\section{Lessons from Experience}

Organizations implementing AG programming are testing ways to connect with AG via phone to share information and understand program needs. In Kenya, a survey of AG's pre-pandemic influences on transitions to adulthood during the COVID-19 pandemic found that approximately one-third (32\%) of AG owned a mobile phone, and a larger percentage of older girls (15-19 years) used mobile phones to access schoolwork than younger AG (1014 years) (34\% compared to $24 \%)^{14}$. These results confirm the potential of using mobile phones to reach girls, particularly older AG, although most respondents shared family mobile phones.

\footnotetext{
13 Girl Effect \& Vodafone Foundation. (2018). Real girls, real lives, connected. https://prd-

girleffectcorp.s3.amazonaws.com/documents/GE VO Full Report -compressed.pdf

14 Bellerose, M., Diaw, M., Pinchoff, J., Kangwana, B., \& Austrian, K. (2020). Pre-pandemic Influences on Kenyan Girls' Transitions to Adulthood during COVID-19, Girlhood Studies, 13(3), 133-150. Retrieved Apr 27, 2021, from
}

In program settings where mobile phone coverage is high, implementers have engaged group participants by holding mentor-led session via group phone calls. In the Keeping Girls in Schools to Reduce Child Marriage in Rural Bangladesh project, sessions included three girls for 15 minutes twice a week. During these sessions, the girls learned about sexual and reproductive health, COVID-19, financial literacy, and English. Initial challenges related to timing and phone use were overcome by allowing flexible scheduling. ${ }^{15}$

Girl MOVE Academy in Mozambique has maintained contact with AG through phone calls and text messages. During a lockdown in Mozambique, the shift to online communications hindered mentors' efforts to connect with program participants because the girls did not all have reliable internet connections; only $6 \%$ of participants owned a mobile phone. ${ }^{16}$ However, staff managed to connect with nearly $70 \%$ of girls initially, increasing to $80 \%$ over time. This increase was largely attributed to modifying tactics for contacting AG. Mentors first contacted participants via a text message with a health knowledge challenge, and then followed up with a phone call a few days later to discuss girls' wellbeing and talk through the challenge. During the first three months of the pandemic, this was paired with weekly physically-distant community visits. The frequency of contact with girls, as well as varied outreach strategies (text message, phone calls, and in-person), helped strengthen relationships between girls and mentors.

\section{Use mentors to deliver health messages and products}

\section{Recommendations}

- $\quad$ Existing mentors, who AG and their families know, can conduct home visits to maintain connection and provide support.

- Train mentors on COVID-19 prevention measures, and additional health messaging or educational information that they will be expected to deliver during household visits.

- Visits must respect local guidelines to reduce the spread of COVID-19 (i.e., face coverings, social distancing, meeting outside in a private location if possible).

https://www.berghahnjournals.com/view/journals/girlhoodstudies/13/3/ghs130310.xml

15 This project is a scale up of Bangladesh's BALIKA project. Briggs, Hannah, Nicole Haberland, Sapna Desai, Thomas de Hoop, and Thoai Ngo. 2020. "The impact of COVID-19 on opportunities for adolescent girls and the role of girls' groups," brief, Evidence Consortium on Women's Groups.

16 https://buildcommunity4girls.org/fieldexperience-covidresponse-2-mozambique/ 


\section{Lessons from Experience}

Mentors for community-based girls' groups, who often are locally-known and respected, are in a unique position to maintain contact with vulnerable AG during phases where movement and interactions within the community are more limited than usual. Leveraging existing mentor capacities is a key strategy that AG programs use to keep participants and mentors safe and maintain connection with beneficiaries.

In settings where group meetings ceased due to pandemic-related restrictions, home visits from mentors presented an alternative strategy for maintaining contact with AG. Benin's Batonga Foundation equipped their mentors to conduct home visits to AG participants and provide hand soap and information on health and hygiene. In Tanzania, Secondary Education for Girls' Advancement (SEGA's) community-based program also mobilized mentors to provide life skills support and distribute personal protective equipment such as masks and soap to program participants. ${ }^{17}$ Mentors in the Secure Futures program in Nairobi, Kenya provided home visits to pregnant adolescents and young mothers to conduct welfare checks and refer AG to counselors for psychosocial support. ${ }^{18}$

\section{Expand Program Priorities to Respond to Shocks}

\section{$\underline{\text { Recommendations }}$}

- Explore how implementers can support AGs and their families beyond the original program aims to mitigate the impact of unforeseen shocks.

- Prioritize efforts to sustain girls' schooling.

\section{Lessons from Experience}

Organizations that implement programs for AG have considered tactics to respond to pandemic-related shocks related to food access, job security, and general health, which may entail supporting $A G$ and their families in new ways. Organizations have considered various ways to support to $A G$ and their families beyond the original aims of girls' groups to respond to emergent challenges. In Tanzania, SEGA

\footnotetext{
${ }^{17}$ Landskroner-Eiger, S. (2020). Nurturing Minds/SEGA School-Driven Response to Covid-19 in Tanzania. In "And still they persist." - 8-Part Series on Community Protection and Revitalization from

the Front Lines of Covid-19 Response" by S. Soares. Adolescent Girls Community of Practice ${ }^{18}$ Briggs, Hannah, Nicole Haberland, Sapna Desai, Thomas de Hoop, and Thoai Ngo. 2020. "The impact of COVID-19 on opportunities for adolescent girls and the role of girls" groups," brief, Evidence Consortium on Women's Groups.

19 Landskroner-Eiger, S. (2020). Nurturing Minds/SEGA School-Driven Response to Covid-19 in Tanzania. In ““And still they persist." - 8-Part Series on Community Protection and Revitalization from the Front Lines of Covid-19 Response" by S. Soares. Adolescent Girls Community of Practice.
}

included food assistance to families in the communities where they work. ${ }^{19}$

A secondary effect of the pandemic is that girls stayed home during school closures, which has been associated with an increase in their domestic responsibilities. The longer the pandemic continues, the greater effect this may have on girls' education and their prospects for returning to school.

Mozambique's Girl MOVE Academy aimed to preempt this dropout challenge by connecting AG to schools through the development and introduction of a "Literacy Game." The game issued challenges for AG to promote their interest in education.

\section{Economic Strengthening}

\section{$\underline{\text { Recommendations }}$}

- In consultation with communities and AG participants in safe space groups, SWEDD can identify ways to support families and AG who face economical and financial instability due to the pandemic.

\section{Lessons from Experience}

The pandemic has damaged the livelihood prospects of $A G$ and their families. ${ }^{20}$ Reduced mobility within and between communities, as well as market closures and restrictions on gatherings, have reduced opportunities for income generation. ${ }^{21} \mathrm{~A}$ possible consequence of the shift in some families' economic situations is that they are forced to let go of their domestic workers. These domestic workers may be AG who end up unemployed and homeless, with limited options for their wellbeing and survival, increasing risks for this already marginalized group. 22

Organizations conducting programming for AG have pivoted to expand AG's economic opportunities. For example, the Center for the Arts in Haiti works with girls to make face masks for distribution and sale within communities. They also provided a small sum of money to AG to maintain handwashing stations (i.e., maintaining water supply, provide soap, etc.) in addition to messaging to promote hand washing in the community. ${ }^{23}$ It is imperative to monitor income generating activities for AG to assess how profits (if any) are used or who receives them.

\footnotetext{
https://buildcommunity4girls.org/fieldexperience-covid-response-5-tanzania/ ${ }^{20}$ Landskroner-Eiger, S. $(2020$

${ }^{21}$ CARE. (2020). COVID-19 could condemn women to decades of poverty: Implications of the COVID-19 pandemic on women's and girls' economic justice and rights. ReliefWeb. https://reliefweb.int/sites/reliefweb.int/files/resources/CARE Implications of COVID19 On WEE 300420 .pdf

Briggs, Hannah, Nicole Haberland, Sapna Desai, Thomas de Hoop, and Thoai Ngo. 2020. "The impact of COVID-19 on opportunities for adolescent girls and the role of girls' groups," brief, Evidence Consortium on Women's Groups.

${ }^{23}$ Adaptations in Crisis is a webinar presented by the Population Council's Adolescent Girls Community of Practice, focused on disseminating information on different models and experiences of girls' programs during COVID-19.
} 